\title{
MÁS ALLÁ DE LA GANADERÍA Y LA AGRICULTURA. LAS EXPORTACIONES ARGENTINAS DE QUEBRACHO, 1890 - 1913
}

\author{
Beyond cattle and agriculture. \\ The Argentine exports of quebracho, 1890 - 1913
}

Agustina Rayes

\section{Resumen}

Tradicionalmente la historiografía ha estudiado las exportaciones ganaderas y agrícolas argentinas durante la Primera Globalización por la centralidad que estos productos tuvieron en la canasta exportadora. Sin embargo, existieron otros artículos con un peso menor en el total exportado, pero que contribuyeron a dibujar un panorama de mayor diversificación. Entre estos últimos, destacaron los productos forestales del Chaco oriental.

En este trabajo nos proponemos reconstruir la trayectoria de las exportaciones de quebracho (en extracto y rollizos) utilizando los Anuarios de la Dirección General de Estadística de la Nación. Adicionalmente, hemos complementado estos datos con fuentes diplomáticas inéditas que nos ayudaron a conocer el desempeño de los distintos destinos.

$<$ Quebracho $><$ Exportaciones argentinas $><$ Primera Globalización $><$ Destinos $>$

\begin{abstract}
Traditionally, historiography has studied Argentine exports of cattle and agricultural goods during the First Wave Globalization because of their central importance in the export basket. Nevertheless, other goods, with less weight in the total value, contributed to a more diversified scene. Among them, forest products of Eastern Chaco stood out.

In this paper, we propose to reconstruct quebracho's (as extract and lumber) export trajectory using the Anuarios de la Dirección General de Estadística de la Nación (Annals from the Direction of National Statistics). In addition, we have enlarged these data with unpublished diplomatic documentation that helped us to better understand the different destinies' performance.
\end{abstract}

$<$ Quebracho $><$ Argentine exports $><$ First wave globalization $><$ Destinies $>$ 


\section{Introducción}

En las últimas décadas del siglo XIX, la Argentina se insertó en los mercados internacionales como exportadora de materias primas y alimentos. Dentro del espectro de bienes vendidos al exterior destacaron aquellos desarrollados por la ganadería - como las carnes frigoríficas, las lanas y los cueros- y la agricultura - como los cereales y las oleaginosas. Sin embargo, existieron intentos de introducir otros artículos cuyo origen de producción fue otro como los artículos forestales, entre los cuales sobresalieron los derivados del quebracho. ${ }^{1}$

En este sentido, nos proponemos reconstruir la trayectoria de las exportaciones del extracto y los rollizos de quebracho entre el último decenio decimonónico y los umbrales de la Primera Guerra Mundial, es decir, detallar los mercados a los que se dirigían, y los factores de determinaron su dinámica. De este modo, procuramos aportar a la comprensión de los alcances y límites que presentó la diversificación exportadora - entendida no como la transformación de un sector productivo a otro, por cuanto se trató en todos los casos de bienes primarios, sino como la variedad de artículos ofrecidos -, más allá de las ramas clásicas de la agricultura y la ganadería, ampliamente estudiadas por la historiografía. Para hacerlo, nos apoyamos en nuestra base de datos creada sobre los Anuarios de la Dirección General de Estadística de la Nación (en adelante ADGEN). Adicionalmente, complementamos el análisis estadístico con el uso de la documentación diplomática inédita del Archivo del Ministerio de Relaciones Exteriores y Culto, especialmente la Serie Diplomática y Consular, y las Memorias del Ministerio de Relaciones Exteriores y Culto (en adelante MREC) elevadas anualmente ante el Congreso Nacional.

\section{La Argentina agroexportadora durante la gran expansión}

El período escogido, particularmente las décadas anteriores a la Primera Guerra Mundial, ha sido retratado por la historiografía económica como el momento más "globalizado" de la historia, al menos en términos de migraciones (Chiswick \& Hatton en Bordo et al., 2003) y flujos de capital (Obstfeld \& Taylor en Bordo et al., 2003). Desde esta perspectiva se ha entendido también que el comercio internacional de commodities creció por la baja en los costos de transporte (O'Rourke \& Williamson, 2000). Ello posibilitó, entre otras cuestiones, la apertura de inmensas cantidades de tierras agrícolas en las zonas templadas abastecieran de alimentos a todo el mundo (Harley, C. K. en Broadberry \& Crafts, 1992), que, sumado al aumento del ingreso per cápita entre las nuevas poblaciones industriales (Ashworth, 1977; Maddison, 1997), se tradujo en un desenvolvimiento significativo del intercambio que marcó para siempre el rumbo de la historia de las relaciones económicas entre países (Lamartine Yates, 1959).

\footnotetext{
${ }^{1}$ Árbol nativo que puede alcanzar los 25 metros de altura y 1,25 metros de diámetro, con follaje ralo, hojas verde oscuro, tronco recto y largo, corteza agrietada de color marrón oscuro, madera dura, pesada y rojiza (Zarrilli, 2008).
} 
Las naciones latinoamericanas no recorrieron el mismo sendero de integración a los mercados internacionales, lo cual dependió de su situación económica en el tiempo final de la colonia, la intensidad y duración de las guerras por la Independencia, el proceso de reacomodamiento interno posterior (Kuntz, 2007) y aquello que Bulmer Thomas (1998) llamara "la lotería de bienes" disponibles para la exportación. No obstante, como rasgos esenciales compartieron la fragmentación y pequeñez de sus mercados internos, la inestabilidad política, la falta de medios de transporte adecuados que integraran los territorios y la herencia de aparatos productivos escasamente desarrollados (Bértola \& Williamson, 2006). Ante ese escenario, cuando los países alcanzaron una situación mínima de estabilidad, tomaron la opción de la integración a los mercados internacionales para salir del contexto de atraso económico, aprovechando la ventana de oportunidad abierta por la nueva demanda generada desde las naciones más avanzadas (Kuntz, 2010).

La etapa 1870-1913 tuvo factores beneficiosos para la integración de América Latina a los mercados externos como la industrialización en Europa y Estados Unidos que intensificó la demanda de bienes primarios, la extensión de los ferrocarriles que permitieron aprovechar territorios agrícolas fértiles y forestales antes inexplotados y los mercados de capital cada vez más complejos que facilitaron la expansión de las importaciones de bienes de consumo e insumos (Cardoso \& Helwege, 1993). En este contexto, la Argentina se insertó como una economía exportadora de materias primas y alimentos, cuyo desempeño general fue en ascenso (Cortés Conde, 1979; 1998).

En un estudio comparativo para América Latina, Luis Bértola y José Antonio Ocampo (2010) estimaron determinadas variables para cada uno de los países, comparando el quinquenio 1870 - 1874 con el de 1910 - 1914. Como resultado, estos autores notaron que en Argentina los términos de intercambio crecieron 1,3 veces (la media latinoamericana fue de 1,1), el poder de compra de las exportaciones aumentó 14,7 veces (la media latinoamericana fue de 5,6) y el poder de compra de las exportaciones per cápita aumentó 3,4 veces (la media latinoamericana fue de 2,6). Según una nueva base creada por nosotros, entre 1875 y 1913 las exportaciones argentinas a precios corrientes se multiplicaron en siete veces y aumentaron en seis veces a precios constantes. En términos absolutos, ello significó aproximadamente un promedio de oro $\$ 61$ millones anuales entre 1875 y 1879 , mientras que el valor de las exportaciones argentinas aumentó a una media de oro $\$ 443$ millones anuales entre 1910 y 1913 (Rayes, 2013a).

Se debe notar que, como señalara Carlos Díaz Alejandro (1983), la experiencia argentina anterior a 1930 concordaba en términos generales con la teoría del comercio y el crecimiento basada en los excedentes. Las exportaciones estuvieron diversificadas, en el sentido anteriormente apuntado, aunque salieron del sector rural y tuvieron escasa elaboración y hubo desconcentración geográfica de destinos, aunque cabe reconocer la dependencia del mercado británico en el comercio de carnes. 
Como explica Eduardo Míguez (2008), en el caso argentino el desarrollo basado en recursos naturales, especialmente aquellos localizados en la pampa húmeda, fue un proceso intensificado desde finales del siglo decimonónico cuando fueron incorporados al sistema productivo, obteniendo una alta rentabilidad marginal, atrayendo capital, tecnología y trabajo. Desde ya, este desempeño se pudo mantener hasta tanto los mercados internacionales respondieron, y mientras la alta productividad en el sector agrario fue suficiente para motorizar un alto rendimiento en el conjunto de la economía.

Acerca de la composición de las exportaciones argentinas cabe destacar que la ganadería fue preponderante durante la década de 1880, puesto que constituyó el origen del $87 \%$ de las exportaciones argentinas, mientras que la agricultura participó en $10,3 \%$ - promedio elevado por la performance desde 1887, dado que había principiado el decenio con una proporción de entre 1,6\% y 6,9\%. En los años 90 s se advierte una injerencia más significativa de los artículos agrícolas del orden del 30,3\%, en línea con las transformaciones productivas, sin embargo, la ganadería representó el $60 \%$ del conjunto de las exportaciones. Y en el primer decenio del siglo XX la agricultura superó a la ganadería con 50,4\% y 46,4\%, respectivamente (Rayes, 2013a).

Esta divisoria tan clara entre agricultura y ganadería en las exportaciones argentinas no sólo permite conocer los orígenes principales de las exportaciones, sino que señala las ausencias en la estructura productiva. La minería, elemento central en la integración a los mercados internacionales en el comparable caso australiano (Vamplew, 1987; Mitchell, 1995; Gerchunoff \& Fajgelbaum, 2006), casi no existió en la Argentina y la producción forestal, uno de los puntales de la economía canadiense (Urquhardt \& Buckley, 1965: Mitchell 1998), estuvo prácticamente alejada del conjunto de las exportaciones, excepto en el caso del quebracho; impresión señalada en la época por el director de los ADGEN, Francisco Latzina, quien consideraba que el comercio exterior argentino consistía en la importación de artículos manufacturados y en la exportación de materias primas, procedentes de la ganadería y agricultura, ya que la minería, las explotaciones forestales y los productos de la caza, contribuían sólo con valores mínimos al aumento de la exportación y la pesca proveía sólo á las necesidades del consumo casero, pero no dejaba excedentes para el intercambio internacional (Latzina, 1905; ADGEN, 1910, p. XIX).

La clasificación de los ADGEN 1894 agrupó las exportaciones por su origen y las dividió en: I) Productos de la ganadería: a) animales vivos, b) despojos animales, c) materias primas elaboradas y d) residuos animales; II) Productos de la agricultura: a) materias primas, b) materias vegetales y c) residuos vegetales; III) Productos forestales; IV) Productos de la minería; V) Productos de la caza y VI) Productos y artículos varios. Entre las exportaciones forestales figuraron las siguientes: carbón vegetal, cedro y quebracho, durmientes, estacones, medios postes y estacones de ñandubay y postes de ñandubay y picanillas, aserrín, rollizos y extracto de quebracho, leña y maderas diversas. Este tipo de productos ocupó el tercer lugar detrás de la ganadería y la agricultura, dado que representaron entre el 1,5\% y el 3,7\% del valor total exportado entre 1890 y 1913 . Aunque, como se ha visto, las exportaciones forestales no fueron 
significativas en términos generales, la explotación del quebracho fue una actividad importante en términos regionales.

\section{Los mercados externos del quebracho argentino}

Sin dudas, los artículos ganaderos y agrícolas dominaron la escena general de las exportaciones argentinas. Sin embargo, dentro de los bienes de origen forestal el caso del quebracho colorado - localizado en el Chaco oriental y vendido en forma de rollizos y como extracto -, merece un lugar en los análisis sobre el desempeño agroexportador, no tanto por su impacto en el total de las ventas al extranjero sino por el potencial que se le reconoció en la época, ya que se trató del principal producto forestal exportado (la participación de los otros fue nula o poco significativa).

Es importante reconocer de antemano que, tal como se observa en cada uno de los ADGEN de la época, durante todo el período aquí estudiado los productos del quebracho estuvieron exentos de derecho. Los únicos que pagaron aranceles entre mediados de 1870 y comienzos del siglo XX fueron bienes pecuarios que tenían una tradición exportadora como las lanas, los cueros y otros subproductos y no se gravaron, en cambio, los productos agrícolas, forestales, de la caza y pesca o de la minería, puesto que se trató de fuentes de las exportaciones no desarrolladas previamente.

La explotación del quebracho es una muestra de que Chaco, área extrapampeana, se incorporó al sistema nacional con una economía primaria exportadora, por cuanto dependió casi enteramente de la demanda externa - menos del 10\% fue consumido por el mercado interior -, fue un negocio del que participaron capitales extranjeros que se nutrieron de insumos foráneos y la extensión de su producción fue necesario un proceso de apropiación de tierras a comunidades originarias (Zarrilli, 2004b).

\section{El extracto de quebracho}

Según se conoce, la industria del tanino de quebracho se originó por un descubrimiento que un grupo de técnicos curtidores franceses y alemanes realizaron en 1850 sobre las propiedades tanantes de esa madera. Luego, en las exposiciones de París de 1855 y 1867 y en la de Buenos Aires de 1872 se difundió aún más (Altamirano, 1999). La primera fábrica taninera se instaló en Peguajó, provincia de Corrientes, cerca del río para aprovechar los recursos hídricos (Zarrilli, 2004c).

La producción forestal estuvo centralizada por pocas compañías (GirbalBlacha, 1993), entre las que intervino el capital inglés (Barsky \& Gelman, 2001) y el alemán (Gori, 1974). El avance de las empresas tanineras ha sido analizada de forma completa y detallada, entre otros, por Bünstorf (1982) y Zarrilli (2008).

Sin embargo, en Argentina el extracto de quebracho apareció en los registros de los ADGEN recién en 1895; desde entonces, las toneladas vendidas al exterior fueron en ascenso. El volumen aumentó exponencialmente de 6.653 toneladas entre 1895 y 1899 a 51.517 toneladas en los primeros cinco años del siglo XX, a 192.097 toneladas 
un quinquenio después y a 331.749 toneladas en los años previos a la Primera Guerra Mundial. Es decir, desde su ingreso al mercado internacional, el quantum creció en 50 veces en el término de casi dos décadas.

Es probable que el precio medio utilizado a lo largo de este período por las estadísticas oficiales no se corresponda con los valores de mercado, ya que es poco factible que el mismo haya estado valuado en oro $\$ 100$ por tonelada todos los años sin producirse variación alguna. En la serie creada por Cortés Conde et al. (1965), referencia de los precios de plaza de los diferentes artículos exportados, tampoco se muestran posibles valores de mercado por la poca incidencia de este producto en la canasta. De cualquier modo, ha sido posible seguir la trayectoria porque el porcentaje de cada socio comercial es relativo al volumen e independiente de los precios medios aplicados.

Desde mediados de 1890 hasta el cambio de centuria, el extracto de quebracho fue exportado principalmente a Alemania, que compró entre la mitad y el $80 \%$ del valor exportado, pero esta tendencia decreció a menos de un cuarto en los primeros años del siglo XX, e incluso, menos de un décimo. En su lugar, aumentó el rol de Estados Unidos, que, de significar entre un cuatro y un quinto del total exportado en el último quinquenio decimonónico, se transformó en el comprador de más de mitad y en algunos años llegó a representar aproximadamente el $70 \%$ de la cantidad total. Por otra parte, también fueron clientes el Reino Unido y Bélgica, que compraron alrededor de un décimo cada uno. Además, complejizaron el panorama Italia, Austria-Hungría y Suiza, los cuales figuraron en la estadística por la introducción de ensayos. ${ }^{2} \mathrm{El}$ gráfico 1, indica la importancia relativa anual de cada socio comercial entre 1890 y 1913 :

Para complementar la información estadística, hemos utilizado informes de las principales legaciones o consulados argentinos en el exterior. El estudio de estas fuentes nos ha permitido conocer el comportamiento de los distintos compradores, sus preferencias y la concurrencia en las diferentes plazas.

Las toneladas enviadas a los mercados germanos fueron en ascenso, no sólo por las importaciones alemanas directas sino por el volumen llegado por los puertos holandeses en tránsito, ${ }^{3}$ especialmente el quebracho oscuro útil para teñir mejor los cueros. ${ }^{4}$ Hamburgo fue el emporio continental del producto por la existencia de numerosas curtiembres ${ }^{5} \mathrm{y}$, en menor medida, también llegó a Bremen.

\footnotetext{
${ }^{2}$ Legación argentina en Italia al Ministerio de Relaciones Exteriores y Culto (en adelante MREC), Roma, 1 de abril de 1901, en Memorias del MREC (1904), p. 171.

${ }^{3}$ Consulado General (en adelante CG) en Países Bajos a MREC, Ámsterdam, 20 de enero 1905, en Archivo del Ministerio de Relaciones Exteriores y Culto (en adelante AMREC), Serie Diplomática y Consular (en adelante SDC), Sección Asuntos Consulares (en adelante SAC), Caja AH/0904, Exp. 2.

${ }^{4} \mathrm{VC}$ en Alemania a MREC, Hamburgo, 28 de febrero de 1901, en AMREC, SDC, Caja AH/0760, Exp. 6.

${ }^{5}$ Cónsul en Alemania a CG, Hamburgo, 8 de febrero de 1893, en AMREC, SDC, Caja AH/0523, Exp. 53 1/3; CG en Alemania a MREC, Hamburgo, 14 de enero de 1905, en AMREC, SDC, SAC, Caja AH/0894, Exp. 4.
} 


\section{Gráfico 1.}

Los destinos de las exportaciones argentinas de extracto de quebracho, 1895 - 1913

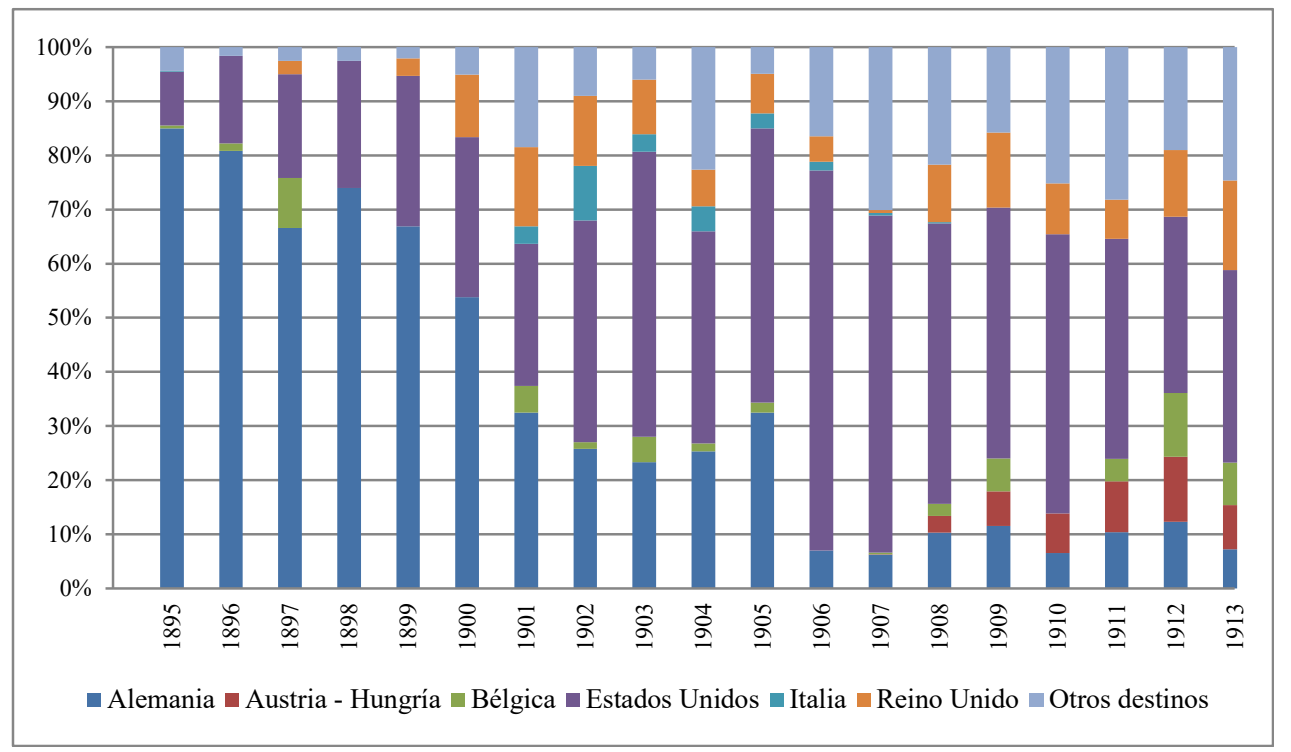

Fuente: Elaboración propia en base a ADGEN (1890 - 1913).

Durante la década de 1890, las importaciones de extracto de quebracho en aquella plaza procedieron de la Argentina, exportadora sin rival dada su superioridad y calidad tanina en los cueros y pieles. ${ }^{6}$ Tal fue la importancia del quebracho como materia tintórea de los cueros alemanes que, a finales de la centuria, cuando la embestida proteccionista del partido agrario fue fuerte y se disparó contra varias importaciones, este producto quedó exento, ya que el creciente consumo fue cinco veces mayor a la producción nacional y no había tiempo suficiente como para desarrollar la industria forestal germana frente a tales necesidades productivas. ${ }^{7}$ Esta situación se repitió en el tiempo, el gremio de los tintoreros se alzó ante los intentos de la Liga Agraria por aumentar los aranceles del quebracho. ${ }^{8}$ Finalmente, el partido agrario presionó para que el Parlamento oyera sus voces y, a comienzos de 1901, los legisladores se hicieron eco del pedido. ${ }^{9}$ Las tarifas aprobadas fueron finalmente de 3 a 5 marcos cada 100 kilogramos de rollizos y de 20 marcos cada 100 kilogramos de extracto, en defensa de los intereses del roble germano, ${ }^{10}$ circunstancia que puso en vilo la venta argentina de

\footnotetext{
${ }^{6}$ CG en Alemania a MREC, Hamburgo, 19 de marzo de 1897, en AMREC, SDC, Caja AH/0628, Exp. 12.

${ }^{7}$ Ministro en Alemania a MREC, Berlín, 30 de marzo de 1899, en AMREC, SDC, Caja AH/0684, Exp. 10.

${ }^{8}$ Legación argentina en Alemania a MREC, Berlín, 26 de enero de 1895 en Memorias MREC (1895).

${ }^{9}$ Vicenconsulado (VC) en Alemania a MREC, Hamburgo, 28 de febrero de 1901, en AMREC, SDC, Caja AH/0760, Exp. 6; CG en Alemania a MREC, Hamburgo, 23 de marzo de 1901, en AMREC, SDC, División Europa y América (en adelante DEA), Caja AH/0890, Exp. 9.

${ }^{10} \mathrm{VC}$ en Alemania a MREC, Hamburgo, 23 de marzo de 1901, en AMREC, SDC, SAC, Caja AH/0760, Exp. 11.
} 
Rayes. Las exportaciones de quebracho.

quebracho, sumada a la quiebra de la casa Reuner \& Cía., la firma mayorista alemana más importante. ${ }^{11}$ De hecho, a partir de ese año este tipo de exportaciones tendieron a disminuir, y lo hicieron más por la rúbrica de un tratado entre Alemania, Italia y Australia, que preveía el aumento de 20 marcos cada 100 kilos de quebracho y 80 marcos cada 100 kilos de extracto de quebracho. ${ }^{12}$

Según las fuentes diplomáticas, en las plazas alemanas concurrentes del quebracho fueron la algarobilla, la tierra japonesa, la tierra catechú, la valonea, ${ }^{13} \mathrm{el}$ roble germano, la cáscara de roble austro-húngaro, los mirobolanes hindúes y la cáscara de mimosa de Australia. ${ }^{14}$ No obstante este amplio espectro de competencia, según la División de Estadística y Economía Rural del Ministerio de Agricultura argentino, el extracto de quebracho argentino, cuya concentración tanante fue del 22\%, compitió específicamente con la cáscara de roble austro-húngara (12\% de tanino), la cáscara mimosa australiana (32\% de tanino) y el mirobalones de India (30\% de tanino). ${ }^{15}$

En Estados Unidos el extracto de quebracho argentino llegó en forma creciente. El producto arribó básicamente por el puerto de Nueva York, que concentró los pedidos de las talabarterías, zapaterías y curtiembres de Boston, Chicago y el estado de Nueva York. ${ }^{16}$ Allí, el quebracho colorado compitió con el Hemlock o cicuta americana y canadiense, la corteza de nogal o roble y otros vegetales. ${ }^{17}$ Promediando la primera década del siglo XX, el proteccionismo norteamericano quiso imponer subas en los aranceles al extracto de quebracho argentino, ${ }^{18}$ apoyado por los productores locales de extracto de nogal. ${ }^{19}$ Tal fue el lobby local que nunca se suprimieron los aranceles, ni aún con la esperanzadora revisión aduanera a la llegada al poder del presidente Woodrow Wilson. ${ }^{20}$

Aunque se tratara de un mercado secundario, según los registros de los ADGEN, Bélgica fue importante como destino del quebracho argentino, puesto que lo

${ }^{11}$ VC en Alemania a MREC, Hamburgo, 28 de febrero de 1901, en AMREC, SDC, Caja AH/0760, Exp. 6; CG en Alemania a MREC, Hamburgo, 23 de marzo de 1901, en AMREC, SDC, DEA, Caja AH/0890, Exp. 9.

${ }^{12}$ Legación alemana en Argentina a MREC, Buenos Aires, Buenos Aires, 14 de marzo de 1905, en AMREC, SDC, DEA, SAC, Caja AH/0890, Exp. s/d.

${ }^{13}$ CG en Alemania a MREC, Hamburgo, 8 de octubre de 1908, en AMREC, SDC, DEA, SAC, Caja AH/1198, Exp. s/d.

${ }^{14}$ CG en Alemania a MREC, Hamburgo, 23 de marzo de 1901, en AMREC, SDC, Caja AH/0890, Exp. 9.

${ }^{15}$ División de Estadística y Economía Rural del Ministerio de Agricultura a MREC, Buenos Aires, s/d 1901, en AMREC, SDC, SAC, Caja AH/0760, Exp. s/d.

${ }^{16}$ CG en Estados Unidos a MREC, Nueva York, 28 de febrero de 1899, en AMREC, SDC, Caja AH/0681, Exp. 27.

${ }^{17}$ CG en Estados Unidos a MREC, Nueva York, 22 de enero 1903, en AMREC, SDC, SAC, Caja AH/0824, Exp. 58 A.

${ }^{18}$ Legación argentina en Estados Unidos a MREC, Washington, 14 de abril de 1909, en AMREC, SAC, Caja AH/1109, Exp. 56.

${ }^{19}$ Legación argentina en Estados Unidos a MREC, Washington, 3 de enero de 1909, en AMREC, SAC, Caja AH/1109, Exp. 1.

${ }^{20}$ Legación argentina en Estados Unidos al MREC E. Bosch, Washington, febrero de 1913 Memorias del MREC (1915), pp. 441- 446. 
que se importaba allí sólo se consumía una parte, mientras el resto seguía su camino a los países vecinos. Como prueba de la relevancia del producto, el Cónsul General en Amberes preparó un informe, publicado en francés en 1897. Según su estudio, las primeras importaciones desde América del Sur habían procedido de Brasil, pero en la década de 1890 la Argentina se había posicionado mejor, puesto que su quebracho tenía mayor nivel de tanino. El extracto de quebracho en Europa se usaba especialmente líquido, sin embargo, el que llegaba de Argentina era mayormente sólido y existían tres establecimientos en Amberes para su molienda. En Bélgica, el artículo fue utilizado para teñir cueros rugosos y lisos, dada su fácil solubilidad. En Luxemburgo, adonde el extracto llegada desde puertos belgas, se empleaba como tanante del algodón. ${ }^{21}$ En la región europea noroccidental, el producto compitió con tinturas naturales locales y otras procedentes de Australia y Asia Menor, especialmente el roble belga y el castaño francés. Los otros proveedores de quebracho blanco y colorado, aunque muy menores, fueron México, Brasil y Paraguay. ${ }^{22}$

Algunas plazas figuraron como posibles clientes de un producto cuya originalidad era uno de sus mayores valores agregados, sin embargo, no quedaron más que en meras intenciones. Un destino que no prosperó fue Francia, que ni siquiera ha figurado con envíos menores al estilo de muestras. Aunque en el Havre hubo un movimiento de importación de maderas tintóreas a mediados de 1890 por la gran cantidad de fábricas de tanantes líquidos y sólidos, ${ }^{23}$ allí no arribó el quebracho argentino en la última década decimonónica. Según las fuentes diplomáticas, en Burdeos comenzó a entrar el producto para una fábrica de Corrèze a comienzos del siglo XX, ${ }^{24}$ por ejemplo, en 1900 fueron introducidas más de 750 toneladas, ${ }^{25}$ sin embargo, en relación a las toneladas totales exportadas ello no fue significativo. Otro destino para el que se ensayaron intentos de introducir el quebracho colorado en trozos triturado para curtir cueros fue Italia. Las tanerías usaron el fruto leñoso del cerro, una especie de encina griega y se pensaba entrar el producto argentino para competirle, pero se necesitó que curtiera el color blanco. ${ }^{26}$

El producto experimentó un gran crecimiento exportador a finales del siglo XIX por su vínculo con las economías industriales europeas y contribuyó a profundizar la explotación de los bosques de quebracho, proceso que se había iniciado unos años antes para enviar los rollizos.

\footnotetext{
${ }^{21}$ CG en Bélgica a MREC, Amberes, 1 de mayo de 1897, en AMREC, SDC, Caja AH/0627, Exp. 13.

${ }^{22}$ CG en Bélgica a MREC, Amberes, 1 de mayo de 1897, en AMREC, SDC, Caja AH/0627, Exp. 13.

${ }^{23}$ CG en Francia a MREC, París, 25 de marzo de 1896, en AMREC, SDC, Caja AH/0602, Exp. 38; Cónsul argentino a MREC, Havre, 30 de marzo de 1901, en AMRECIC, SDC, ACC, Caja AH/0765, Exp. s/d.

${ }^{24}$ Consulado argentino a MREC, Burdeos, 15 de febrero de 1901, en AMRECIC, SDC, ACC, Caja AH/0765, Exp. s/d.

${ }^{25}$ CG en Francia a MREC, París, 28 de febrero de 1901, en AHCA, SDC, Caja AH/0765, Exp. 21.

${ }^{26}$ Legación argentina en Italia en MREC, Roma, 31 de diciembre de 1892 en Memorias MREC (1893).
} 


\section{Los rollizos de quebracho}

Otra forma que tomaron las exportaciones de quebracho fue el envío de la madera cual rollizos. A diferencia del extracto, esta clase de productos había sido impulsada como exportación al menos una década antes, y por ello, su aumento sorprende menos. Según los registros de los ADGEN, el volumen de este producto fue creciente, ya que entre 1890 y 1894 significó 230.751 toneladas, 739.526 toneladas cinco años más tarde, 1.137.402 toneladas en el primer quinquenio del siglo XX, 1.311.804 toneladas durante el segundo y 1.735 .433 toneladas en los cuatro años anteriores a la Primera Guerra Mundial. Es decir, las cantidades exportadas crecieron 7,5 veces entre 1890 y 1913.

Según la División de Estadísticas y Economía Rural del Ministerio de Agricultura argentino, el rollizo de quebracho fue usado para la construcción de postes, vigas, durmientes y leña, ${ }^{27}$ especialmente porque su madera es dura, fuerte, pesada y difícilmente putrescible. Uno de los rasgos distintivos fue que gran parte de los envíos se hicieron "por órdenes" a las posesiones británicas desde 1895, particularmente a las islas de Falmouth y el Canal de la Mancha y desde allí se redirigían según las condiciones de mercado a diferentes plazas europeas. La historiografía nunca ha distribuido esta clase de exportaciones (Vázquez Presedo, 1971; Mitchell, 1998; Ferreres, 2010) y los mismos fueron distribuidos por primera vez en nuestra obra (Rayes, 2013a). En consecuencia, en los estudios no se han conocido los destinos definitivos de las exportaciones de rollizos de quebracho.

En este trabajo, hemos distribuido este tipo de embarques siguiendo la investigación de Ricardo Pillado, publicada por Francisco Latzina en el ADGEN correspondiente al año 1907. Entonces, Pillado, Director de la División Comercial del Ministerio de Agricultura, conoció el destino definitivo del volumen de importación por distintos socios comerciales entre 1901 y 1905. Dado que la información fue registrada en volumen, resultó necesario pasarla a valores en pesos oro. Para ello, utilizando los volúmenes de exportación, se estimó qué porcentaje de las exportaciones tuvieron destino "a órdenes". Aplicando ese porcentaje al valor total de las exportaciones de los rollizos de quebracho en pesos oro para el quinquenio, se obtuvo el monto que fue exportado con esa modalidad entre 1901 y 1905 . Utilizando los porcentajes que recibió cada destino, se calculó la distribución de los montos exportados en cada destino. En resumen, Alemania compró el 55\% de los embarques "a órdenes", Bélgica el 13\%, Francia el 9\%, los Países Bajos el 8\%, Austria-Hungría el 4\% y el Reino Unido el 3\% (Rayes, 2013b).

De acuerdo a la nueva base estadística creada, los principales compradores de este producto argentino fueron el Reino Unido, destino al que llegó aproximadamente tres cuartos del total exportado hasta mediados de 1890, luego las plazas británicas no alcanzan a comprar ni un décimo. Alemania significó la mitad del total, y Francia y Bélgica compraron menos de un décimo. A continuación, mostramos un gráfico en el

${ }^{27}$ División de Estadística y Economía Rural del Ministerio de Agricultura a MREC, Buenos Aires, s/d 1901, en AMREC, SDC, SAC, Caja AH/0760, Exp. s/d. 
que se expresa la participación relativa anual de los distintos socios comerciales entre 1890 y 1913 :

\section{Gráfico 2}

Los destinos de las exportaciones argentinas de rollizos de quebracho, 1890 - 1913

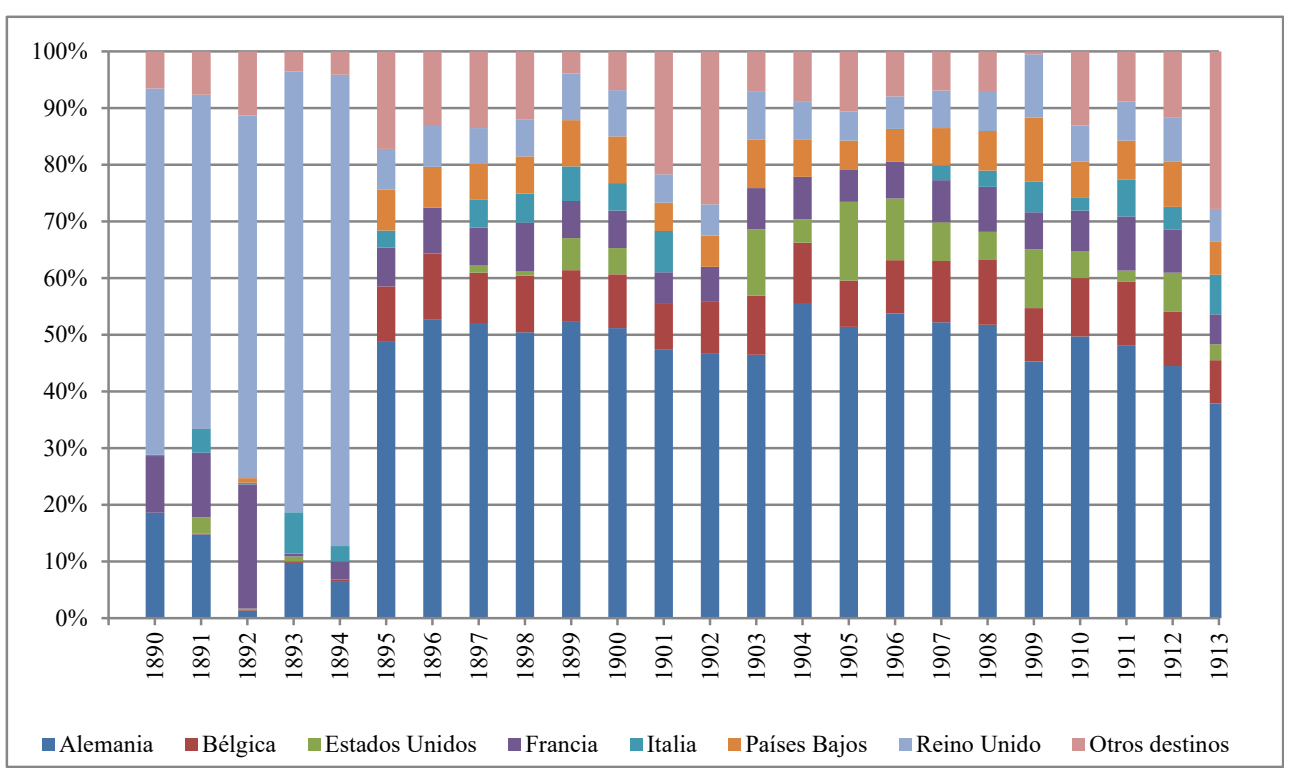

Fuente: Elaboración propia en base a ADGEN (1890 - 1913).

Como hicimos con el análisis del extracto, usamos las fuentes diplomáticas para complementar la información estadística oficial. En este sentido, podemos afirmar que los rollizos se introdujeron en el Reino Unido, que recibía maderas procedentes de los más diversos lugares como Rusia, Suecia, Noruega, Mar Blanco y Norteamérica, ${ }^{28}$ tal como ocurrió con Francia, ${ }^{29}$ especialmente en Burdeos. ${ }^{30}$ Aunque no se observan exportaciones a Brasil en los ADGEN, en Rio Grande Do Sul fueron requeridos los rollizos de quebracho argentinos para los durmientes de ferrocarril por su calidad. ${ }^{31}$ Estados Unidos fue un destino que se proyectó, pero por proximidad geográfica, fueron clientes de las maderas canadienses y fue casi imposible para las especies argentinas competir contra aquellos vecinos. ${ }^{32}$

\footnotetext{
${ }^{28}$ CG en Reino Unido a MREC, Londres, 3 de marzo de 1897, en AMREC, SDC, Caja AH/0625, Exp. 23.

${ }^{29}$ Ministro de Francia en Argentina a MREC, Buenos Aires, 30 de junio de 1891, en AMREC, SDC, Caja AH/0477, Exp. 18.

${ }^{30} \mathrm{CG}$ en Francia a MREC, París, 28 de febrero de 1901, en AMREC, SDC, Caja AH/0765, Exp. 21.

${ }^{31}$ Consulado en Brasil a CG, Río Grande del Sud, 20 de enero de 1893, en AMREC, SDC, Caja AH/0519, Exp. 15.

${ }^{32}$ CG en Estados Unidos a MREC, Nueva York, 7 de enero de 1893, en AMREC, SDC, Caja AH/0519, Exp. 10.
} 
El caso del quebracho es interesante, además, porque de todas las exportaciones argentinas fue la única en la época que existió preocupación entre los diplomáticos, interesados en colocar en los mercados foráneos los diferentes bienes argentinos, por el agotamiento de los recursos naturales. No obstante el promisorio negocio, en Hamburgo, plaza compradora de estos bienes argentinos, se advirtió sobre el peligro de devastar esta madera para su exportación, especialmente para el uso de los rieles del ferrocarril, ${ }^{33}$ una de las aplicaciones de los rollizos de quebracho. También en Amberes y en el prólogo de los ADGEN $^{34}$ se alertó sobre la destrucción de los bosques en el Chaco oriental. ${ }^{35}$ Pero estas alarmas no pusieron coto a una explotación que por esta época fue creciendo sino mucho más tarde, tal como se puede seguir en los volúmenes anuales, que tendieron a duplicarse durante la Gran Guerra y se mantuvieron en un nivel elevado hasta principios de la década de 1930.

De hecho, la actitud de los diplomáticos y los estadígrafos respecto a la explotación del quebracho ha contrastado hasta finales de la década de 1940 con las leyes nacionales forestales, y especialmente las provinciales, que privilegiaron los recursos fiscales por sobre la preservación de los bosques (Zarrilli, 2004a). Los bosques se explotaron con criterios meramente extractivos, sin prever su reposición ni planificación económica y transformándolos en recursos no renovables (Zarrilli, 2004b).

\section{Conclusiones}

Entre finales del siglo XIX y los umbrales de la Primera Guerra Mundial la Argentina se insertó en los mercados internacionales como productora de alimentos y de materias primas, requeridos masivamente en aquellas economías que transitaban procesos de industrialización. Dentro de este contexto, y tal como se ha mostrado con el trabajo de las estadísticas de los ADGEN, el quebracho no fue un bien significativo en la canasta exportadora argentina entre 1890 y 1913 . No obstante, es preciso señalar su relevancia en términos de diversificación de mercados, ya que llegó a diferentes países europeos, Estados Unidos y países vecinos como Brasil. Además se trató del principal producto exportado fuera de la matriz bipartita ganadería - agricultura que regló la composición del comercio y fue un recurso natural localizado allende la región económicamente más importante, la pampa húmeda, ya que se ubicó en el área chaqueña oriental.

Según las fuentes diplomáticas abordadas en este trabajo, vendido como extracto, el quebracho colorado fue bienvenido en distintas curtiembres europeas y norteamericanas, adonde llegó favorecido por su potencialidad tanante, pero concurrió con otros productos afines, especialmente locales, que conllevaron la ejecución de medidas proteccionistas que entorpeció su arribo. Comerciado como rollizo,

\footnotetext{
${ }^{33}$ CG en Alemania a MREC, Hamburgo, 19 de marzo de 1897, en AMREC, SDC, Caja AH/0628, Exp. 12.

${ }^{34}$ ADGEN, 1913, p. XXVII.

${ }^{35}$ CG en Bélgica a MREC, Amberes, 1 de mayo de 1897, en AMREC, SDC, Caja AH/0627, Exp. 13.
} 
el quebracho se destinó al Reino Unido, Bélgica y Alemania, muy apreciado para la construcción de rieles y la construcción de viviendas. En todas las plazas en que participó, este bien resultó altamente competitivo y, aunque excede el marco temporal aquí escogido, finalmente chocó con las posibilidades extensivas de la producción por los recursos naturales nacionales y no pasó de constituir una prueba de una desviación menor en la estructura exportadora agropecuaria.

\section{Fuentes}

Anuarios de la Dirección General de Estadística de la Nación (1890 - 1913).

Memorias del Ministerio de Relaciones Exteriores y Culto presentadas al Congreso Nacional.

Serie Diplomática y Consular del Archivo del Ministerio de Relaciones Exteriores y Culto de Argentina.

\section{Referencias bibliográficas}

Altamirano, Marcos. 1999. "Historia de la industria taninera en La Verde (Chaco)". En: Folia Histórica del Nordeste, $\mathrm{N}^{\circ} 14$, Resistencia, Instituto de Investigaciones GeohistóricasConicet, Instituto de Historia- UNNE.

Ashworth, William. 1977. Breve historia de la economía internacional (desde 1850), México, Fondo de Cultura Económica.

Barsky, Osvaldo y Gelman, Jorge. 2001. Historia del agro en la Argentina: desde la conquista hasta el siglo XX, Buenos Aires, Grijalbo - Mandadori.

Bértola, Luis \& Williamson, Jeffrey. 2003. "Globalization in Latin America before 1940", En: Working Papers NBER, 9667, National Bureau of Economic Research. y Ocampo, José Antonio.2010. Desarrollo, vaivenes y desigualdad. Una historia económica de América Latina desde la Independencia, Secretaria General Iberoamérica.

Bordo, Michael D., Taylor, Alan M. y Williamson, Jeffrey G. (eds.). 2003. Globalization in Historical Perspective, Chicago, Chicago University Press.

Broadberry, S.N y Crafts, N.F.R. 1992. Britain in the International Economy, Cambridge, Cambridge University Press.

Bulmer Thomas, Víctor. 1998. La historia económica de América Latina desde la independencia, México, Fondo de Cultura Económica.

Bünstorf, Jürgen. 1982. "El papel de la industria taninera y de la economía agropecuaria en la ocupación del espacio chaqueño". En: Folia Histórica del Nordeste, $\mathrm{N}^{\circ}$ 5, Resistencia, Instituto de Investigaciones Geohistóricas-Conicet, Instituto de Historia- UNNE.

Cardoso, Eliana y Helwege, Ann. 1993. La economía latinoamericana. Diversidad, tendencias y conflictos, México, Fondo de Cultura Económica.

Cortés Conde, Roberto, Halperin Donghi, Tulio y Gorostegui de Torres, Haydée. 1965. Evolución del Comercio Exterior Argentino I. Exportaciones (mimeo). . 1979. El progreso argentino 1880-1914, Buenos Aires, Editorial Sudamericana, 1979.

Cortés Conde, Roberto. 1998. Progreso y declinación de la economía argentina, Buenos Aires, Fondo de Cultura Económica.

Díaz Alejandro, Carlos F. 1983. Ensayos sobre la historia económica argentina, Buenos Aires, Editorial Amorrortu.

Ferreres, Orlando (dir.). 2010. Dos Siglos de Economía Argentina (1810-2010). Historia argentina en cifras, Buenos Aires, El Ateneo. 
Rayes. Las exportaciones de quebracho.

Gerchunoff, Pablo y Fajgelbaum, Pablo. 2006. ¿Por qué Argentina no fue Australia? Una hipótesis sobre un cambio de rumbo, Buenos Aires, Siglo XXI Editorial.

Girbal-Blacha, Noemí. 1993. "Explotación forestal, riesgo empresario y diversificación económica: las inversiones argentinas en el Gran Chaco (1905-1930)". En: Revista de Historia de América, № 116, México, IPGH, 1995, pp. 29-57.

. "Inserción de una región marginal en la Argentina agroexportadora. El Gran Chaco Argentino y la explotación forestal. 1895-1914”. En: Academia Nacional de la Historia, Octavo Congreso Nacional y regional de Historia Argentina, tomo V, Buenos Aires, Academia Nacional de la Historia, pp. 297-314.

Gori, Gastón. 1974. La Forestal. La tragedia del quebracho colorado, Buenos Aires, Editorial Platina / Stilcograf.

Kuntz Ficker, Sandra. 2007. El comercio exterior de México en la era del capitalismo. 18701929, México, El Colegio de México.

. 2010. Las exportaciones mexicanas durante la primera globalización. 1870-1929, México, El Colegio de México.

Latzina, Francisco. 1905. Estadística Retrospectiva del Comercio Exterior Argentino 1875 1904, Buenos Aires Compañía Sud Americana de Billetes de Banco.

Maddison, Angus. 1997. La economía mundial, 1820-1992: análisis y estadísticas, París, OCDE.

Míguez, Eduardo. 2008. Historia económica de la Argentina. De la conquista a la crisis de 1930, Buenos Aires, Editorial Sudamericana.

Mitchell, Brian R. 1995. International Historical Statistics. Africa Asia and Oceania, 17501988, Basingstoke, Inglaterra., Macmillan Press Ltd.

1998. International Historical Statistics. The Americas, 1750- 1993, Londres, Macmillan.

Rayes, Agustina. 2013a. En las puertas del Dorado. Las exportaciones argentinas, 1890 - 1913, Tesis Doctorado en Historia, Buenos Aires, Universidad Torcuato Di Tella. . 2013b. "“Bestias negras de la estadística". Las exportaciones argentinas "a órdenes", 1895 - 1913". En: Estadística e Sociedade, № 3, Porto Alegre, Asociación de las Américas para la Estadística y el Cálculo de las Probabilidades.

Urquhardt, M.C., \& Buckley, K.A.H., (ed.). 1965. Historical Statistics of Canada, Toronto, Macmillan Co.

Vamplew, Wray (ed.). 1987. Australians Historical Statistics, Fairfax, Symw \& Weldon Associates, New South Wales.

Vázquez Presedo, Vicente. 1971. Estadísticas históricas argentinas (comparadas). Primera parte (1875 - 1914), Buenos Aires, Ediciones Macchi.

Zarrilli, Adrián Gustavo. 2004a. "Historia y economía del bosque chaqueño: la mercantilización de los recursos forestales (1890-1950)". En: Anuario del IEHS, № 19, Tandi, UNCPBA, 2004, pp. 255-283. . 2004b. "La explotación forestal de los bosques chaqueños argentinos (1895-1948)". En: Diálogos. Revista Electrónica, vol. 4, N², Escuela de Historia, Universidad de Costa Rica. . 2004c. "Transformación ecológica y precariedad económica en una región económica marginal. El Gran Chaco argentino, 1890-1950”. En: Barriera, Darío y Roldán, Diego (comp.), Territorios, espacios, sociedades: agenda de problemas y tendencias de análisis, Rosario, Editorial de la Universidad Nacional de Rosario.

. 2008. "El oro Rojo. La industria del tanino en la Argentina (1890-1950)". En: Silva Lusitana, $\mathrm{N}^{\circ} 16$ (2), Lisboa, pp. 239-259. 